\title{
MATERIALS AND INTERFACES
}

\section{Microwave Dielectric Heating Behavior of Supported $\mathrm{MoS}_{2}$ and Pt Catalysts}

\author{
Xunli Zhang, † David O. Hayward,* and D. Michael P. Mingos ${ }^{\ddagger}$ \\ Department of Chemistry, I mperial College of Science, Technology and Medicine, \\ South Kensington, London SW7 2AY, U.K.
}

The temperature of supported $\mathrm{MoS}_{2}$ and Pt catalysts was measured during microwave heating at constant input power by inserting a thermocouple into the center of the catalyst bed immediately after the microwave power had been turned off at the end of progressively longer heating times. Thermal runaway was observed with $\mathrm{MoS}_{2} / \mathrm{Al}_{2} \mathrm{O}_{3}$ and $\mathrm{Pt} / \mathrm{Al}_{2} \mathrm{O}_{3}$ at temperatures in the range $285-300{ }^{\circ} \mathrm{C}$ when the power absorbed rose with temperature at a rate greater than that at which heat is lost by cooling. This condition was not attained with $\mathrm{MoS}_{2} / \mathrm{SiO}_{2}$, and thermal runaway was not observed. F or the $\mathrm{MoS}_{2}$ catalysts, the fraction of the microwave power absorbed, $\gamma$, was found to vary with temperature according to the equation $\gamma=\mathrm{C}_{\mathrm{A}}+\mathrm{C}_{\mathrm{M}}$ $\exp \left(-E_{a} / R T\right)$, where $c_{A}$ and $C_{M}$ are constants and the activation energy, $E_{a}$, is $9.3 \mathrm{~kJ} \mathrm{~mol}^{-1}$ for $\mathrm{MoS}_{2} / \mathrm{Al}_{2} \mathrm{O}_{3}$ and $11.1 \mathrm{~kJ} \mathrm{~mol}{ }^{-1}$ for $\mathrm{MoS}_{2} / \mathrm{SiO}_{2}$.

\section{Introduction}

It is well-known that heat can be generated in dielectric materials by the application of high-frequency electromagnetic radiation. A number of supported catalysts have been heated by this method, and considerable enhancement in reaction rates and/or selectivity has been observed. ${ }^{1-9}$ The reasons for the improved performance are not fully understood, but selective heating of parts of the catalyst, together with other types of temperature variation across the catalyst bed, has been considered as a possible explanation. ${ }^{8-15}$ In a recent study of the reaction of sulfur dioxide with methane over $\mathrm{MoS}_{2} /$ al umina catalysts using mi crowave heating, ${ }^{16}$ we observed the partial conversion of $\gamma$-alumina to $\alpha$ alumina. This reaction occurs only at very high temperatures, far in excess of the measured temperature. A possible explanation for this observation is that localized thermal runaway has occurred in parts of the catalyst bed. This type of phenomenon can be found whenever the microwave power absorbed by the catalyst increases with temperature at a rate greater than that at which heat is lost from the catalyst. Such thermal runaway has been observed with al umina ${ }^{17}$ at temperatures of $650-700{ }^{\circ} \mathrm{C}$ and with borosilicate glass ${ }^{18}$ at $450^{\circ} \mathrm{C}$.

In this paper, we examine the factors that control the microwave heating of a variety of supported catalysts and the conditions under which thermal runaway can occur. Catalysts were heated at constant input power, and the reflected power was measured as a function of

* To whom correspondence should be addressed. Tel: ++44 207594 5726. Fax: ++44 207594 5804. E-mail: d.hayward@ ic.ac.uk.

† Present address: Department of Chemistry, University of Hull, Hull HU6 7RX, England.

‡ Present address: St. Edmund Hall, University of Oxford, Oxford OX1 4AR, England. catalyst temperature with the aid of a directional coupler. The temperatures reached by the catalyst after various heating times were measured by inserting a thermocouple into the center of the catalyst bed immediately after the microwave power had been switched off and extrapolating the temperature readings to zero cooling time. In this way, it was possible to compare the power absorbed by the catalyst with the rate of heat loss after various heating times and thus to find the conditions that lead to instability. The catalysts that have been used are $\mathrm{MoS}_{2} / \mathrm{Al}_{2} \mathrm{O}_{3}, \mathrm{Pt} / \mathrm{Al}_{2} \mathrm{O}_{3}$ and $\mathrm{MoS}_{2} /$ $\mathrm{SiO}_{2}$. This choice allows for the effects of the support and the catalyst material to be compared.

\section{Some Theoretical Aspects of Thermal Runaway}

Before examining the data obtained, it is useful to consider the general conditions under which thermal runaway can occur.

(a) Microwave Power Dissipated in the Catalyst. It can be shown ${ }^{19}$ that the average power dissipated in a dielectric of volume $V$ is related to the electric field $\mathbf{E}$ by the equation

$$
P_{a b s}=\frac{1}{2} \omega \epsilon_{0} \epsilon_{\text {eff }}^{\prime \prime} \int_{V}(E * \cdot E) d V
$$

where $\omega$ is the angular frequency of the radiation, $\epsilon_{0}$ is the permittivity of free space, and $\epsilon_{\text {eff }}^{\prime \prime}$ is the complex component of the relative permittivity of the dielectric, also known as the effective relative dielectric loss factor. Normally, the strength of the electric field will vary throughout the sample, but if the electric field strength is assumed to be constant, eq 1 becomes

$$
\mathrm{P}_{\mathrm{abs}}=\frac{1}{2} \omega \epsilon_{0} \epsilon_{\text {eff }}^{\prime \prime} \mathrm{E}^{2} \mathrm{~V}
$$


With the substitutions $1 / 2 E^{2}=E_{r m s}{ }^{2}$ and $\omega=2 \pi f$, where $\mathrm{f}$ is the frequency, the power absorbed can be written as

$$
P_{\text {abs }}=2 \pi f \epsilon_{0} \epsilon_{\text {eff }}^{\prime \prime} E_{r m s}^{2} V
$$

(b) Rate of Heat Loss from the Catalyst. Following Coel ho, ${ }^{20}$ we consider a simple model in which the catalyst is assumed to be heated to a spatially uniform temperature $T_{s}$ by microwave radiation. Although this model ignores the temperature gradient that must necessarily exist between the center and the periphery of the catalyst, it should be adequate for our purpose, which is to explore, in general terms, the conditions under which thermal runaway can occur. More sophisticated treatments, in which the temperature gradient is taken into account, require a knowledge of the variation of the effective dielectric loss factor with temperature and generally lead to equations for which there are no analytical solutions.

At low temperatures, the main source of heat loss is likely to be conduction through the walls of the quartz tubing in which the catalyst is held. Despite the composite nature of the cooling process, it can be shown that, for radial heat flow under steady-state conditions, the rate of heat loss will be directly proportional to the difference between the temperature of the sample $T_{s}$ and the ambient temperature $\mathrm{T}_{0 .}{ }^{21}$ This can be represented by the equation

$$
\text { rate of heat loss }=\alpha\left(T_{s}-T_{0}\right)
$$

where $\alpha$ is the heat transfer coefficient. At higher temperatures, radiative losses are likely to dominate, with the rate of heat loss being proportional to $\mathrm{T}^{4}$, but for the systems discussed in this paper, eq 4 will be appropriate. It will be shown later that the data obtained in this paper follow this simple equation very well.

(c) Conditions Required to Achieve a Steady Temperature. The rate of rise of temperature during microwave heating is given by the equation

$$
C_{p}\left(\frac{d T_{s}}{d t}\right)=2 \pi f \epsilon_{0} \epsilon_{\text {eff }}^{\prime \prime} E_{r m s}^{2} V-\alpha\left(T_{s}-T_{0}\right)
$$

where $C_{p}$ is the heat capacity of the sample. Provided that the relative dielectric loss factor, $\epsilon_{\text {eff }}^{\prime \prime}$, does not vary greatly with temperature, the material will heat rapidly at first and then reach a steady state, at which the rate at which power is absorbed will be equal to the rate of heat loss from the sample. Thus, the temperature at the steady state will be given by the equation

$$
\alpha\left(T_{s}-T_{0}\right)=2 \pi f \epsilon_{0} \epsilon_{\text {eff }}^{\prime \prime} E_{r m s}{ }^{2} V
$$

In many instances, however, the relative dielectric loss factor shows a strong variation with temperature, and this can sometimes lead to a thermal runaway in which the temperature continues to rise uncontrollably. The achievement of a steady temperature then depends on whether there are solutions to eq 6 . In general, analytical solutions of this equation are not possible, but solutions can be found by plotting the two terms separately and observing the crossover points. This is done in Figure 1, which shows a diagram of absorbed microwave power, $\mathrm{P}_{\mathrm{abs}}$, versus temperature for three different fixed values of the input power, $P_{\text {in }}$. Because

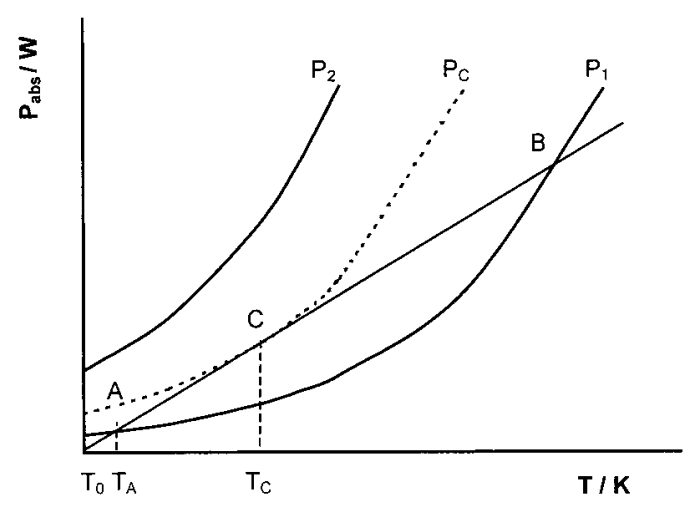

Figure 1. Power-temperature graph for thermal breakdown. (The straight line represents the rate of heat loss from the sample, and the curves represent the heat dissipated in the sample for various values of applied power.)

the effective dielectric loss factor of the catalyst, $\epsilon_{\text {eff, }}^{\prime \prime}$ tends to increase with temperature, the plot of $\mathrm{P}_{\mathrm{abs}}$ versus temperature will curve upward, as shown. The rate of heat loss from the catalyst is represented by the straight line, the assumption being that the rate of loss of heat is proportional to the temperature difference, as indicated by eq 4 .

It can be seen that, when the input power is small $\left(P_{1}\right)$, the exponential curve crosses the straight line at two points, $A$ and $B$. If the initial temperature is $T_{0}$, then the sample will heat up to $T_{A}$, where the rate of heat loss will balance the rate of heat input. If the sample temperature happens to rise above $T_{A}$, perhaps because of a temporary surge in the input power or a fluctuation in $\epsilon_{\text {eff }}^{\prime \prime}$, the rate of heat loss will exceed the rate of heat generation, and the sample will cool back to $T_{A}$. Consequently, $T_{A}$ is a stable temperature. On the other hand, the second crossover point represents an unstable situation in which any small fluctuation will lead to the temperature either falling or rising uncontrollably.

A different situation applies when the power input in Figure 1 is raised to $P_{2}$. Now the exponential curve lies above the straight line, and the sample temperature will continue rising until the sample melts or decomposes or electrical breakdown occurs. There is a critical power input, $\mathrm{P}_{c}$, and a critical temperature, $\mathrm{T}_{c}$, at which the exponential curve just touches the straight line. For input powers less than $P_{c}$, the sample should heat up to a steady temperature, but for input powers above $\mathrm{P}_{\mathrm{C}}$, the temperature will continue to rise uncontrollably.

\section{Experimental Section}

Molybdenum sulfide catalysts, supported on either $\gamma$-alumina or silica, were prepared by impregnating the support material with ammonium heptamolybdate solution. After being dried and calcined at $500{ }^{\circ} \mathrm{C}$, the catalysts were sulfided with an $\mathrm{H}_{2} \mathrm{~S} / \mathrm{H}_{2}$ gas mixture at $400{ }^{\circ} \mathrm{C}$ for a period of $2 \mathrm{~h}$. The loadings of ammonium heptamolybdate were cal culated to give between 2 and 8 wt \% of $\mathrm{MoS}_{2}$ on alumina and $8 \%$ on silica, the assumption being that all of the molybdenum was converted to sulfide. It will be shown later that some of the molybdenum adsorbed onto alumina supports is resistant to sulfidation and that the true percentage of $\mathrm{MoS}_{2}$ on alumina is likely to be lower than the calculated value. Neverthel ess, the calculated values will be used when referring to these catalysts. 


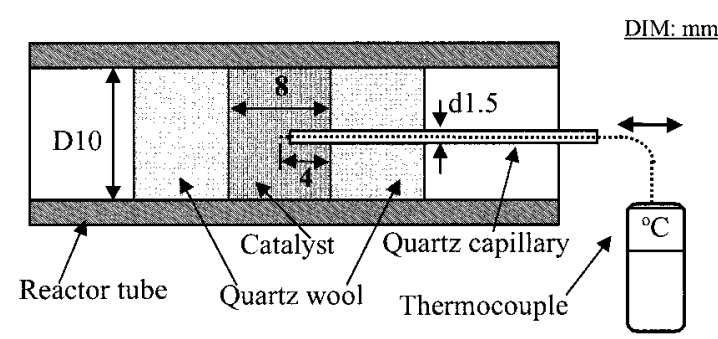

Figure 2. Schematic of the packed-bed reactor with the thermocouple inserted.

An $8 \%$ Pt/alumina catalyst was also prepared by impregnating alumina with the required amount of chloroplatinic acid and then calcining at $500^{\circ} \mathrm{C}$ for $2 \mathrm{~h}$. The sample was then reduced in hydrogen at $400{ }^{\circ} \mathrm{C}$ for $1 \mathrm{~h}$ before use. X-ray diffraction data taken on the catalyst both before and after microwave heating showed weak peaks for platinum, and from the extent of line broadening, it was estimated that the Pt particles must be somewhat less than $100 \mathrm{~nm}$ across. These small Pt particles were not detected by scanning electron microscopy. All of the catalysts had alumina support particles in the size range of $152-178 \mu \mathrm{m}$.

The packed-bed tubular reactor was constructed from quartz tubing with an internal diameter of $10 \mathrm{~mm}$, and the catalyst sample was held in place by two quartz wool plugs, as shown in Figure 2. The catalyst was placed at the center of a cylindrical microwave cavity, which could be tuned by two adjustable stubs. A directional coupler was inserted into the microwave guide system so that the amount of microwave power reflected from the cavity could be measured.

A capillary tube with an external diameter of $1.5 \mathrm{~mm}$ was inserted into the catalyst bed to provide access for a chromel/alumel thermocouple (J ENWAY, with a probe diameter of $0.5 \mathrm{~mm}$ ). The temperature reached by the catalyst during microwave heating was measured by inserting the thermocouple into the bed as soon as possible after the microwave power had been turned off. The temperature decay curve was then recorded on a strip chart recorder, and the temperature was extrapolated to zero time. In practice it took about $2 \mathrm{~s}$ to insert the thermocouple, and an additional $5 \mathrm{~s}$ or so were needed before reliable temperatures could be measured. All temperature measurements were made with argon flowing through the catalyst bed under atmospheric pressure.

\section{Results and Discussion}

(a) Measurement of Temperature from the Cooling Curve. Figure 3 shows typical cooling curves obtained with an $8 \% \mathrm{MoS}_{2} /$ alumina catalyst after it had been heated at 80-W microwave input power for different periods of time. The rate of cooling can be obtained from eq 5 by setting the heat input term to zero; thus

$$
C_{p}\left(\frac{d T_{s}}{d t}\right)=-\alpha\left(T_{s}-T_{0}\right)
$$

After rearrangement and integration, this equation becomes

$$
\left(T_{\mathrm{s}}-\mathrm{T}_{0}\right)=\left(\mathrm{T}_{\max }-\mathrm{T}_{0}\right) \exp (-\mathrm{ct})
$$

where $T_{\max }$ is the temperature of the sample at $t=0$ and $c=\alpha / C_{p}$. The cooling data were found to fit this

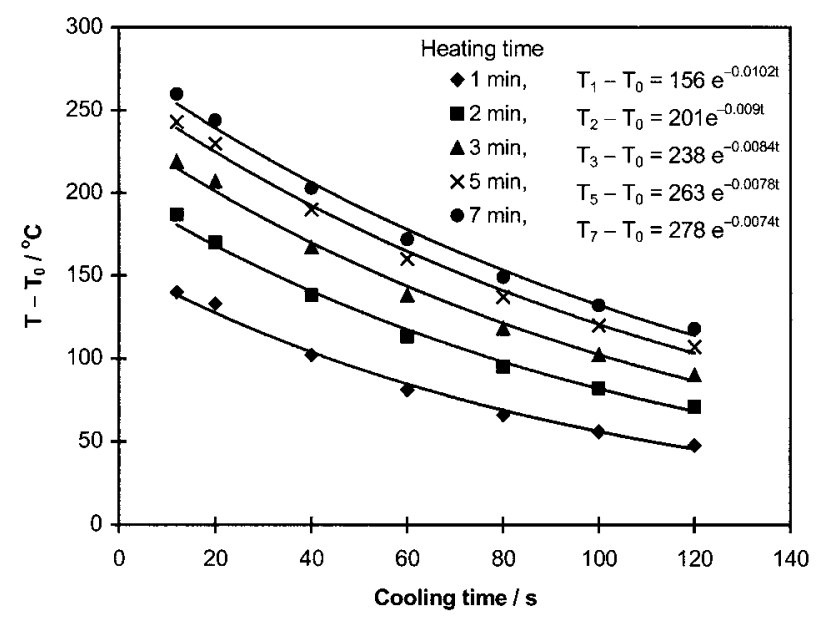

Figure 3. Cooling curves for an $8 \% \mathrm{MoS}_{2} /$ alumina catalyst after microwave heating for different periods of time. Microwave power input $=80 \mathrm{~W}$.

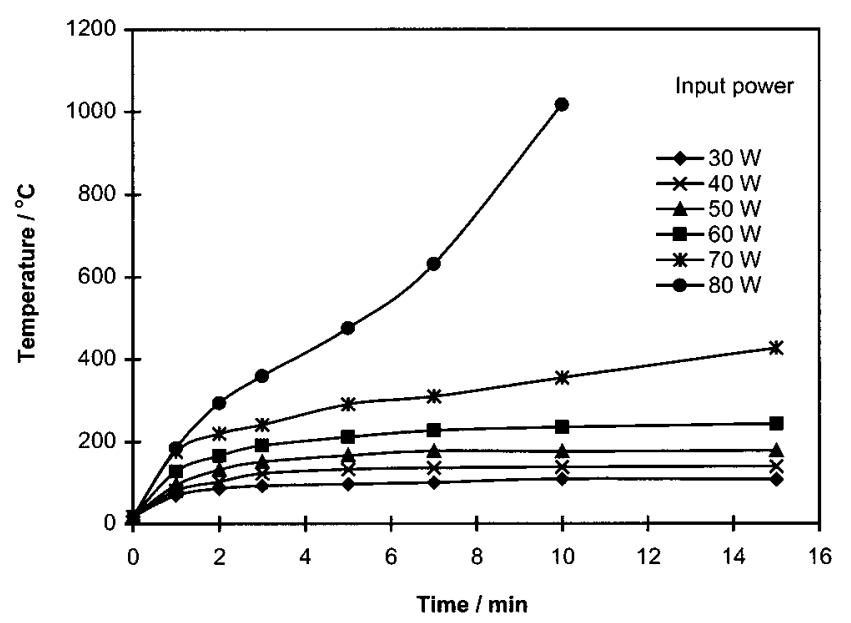

Figure 4. Temperature versus time for microwave heating of a nominal $8 \% \mathrm{MoS}_{2} /$ alumina catalyst at different input power levels.

equation quite well, as shown by the good agreement between the theoretical lines and the data points, but the cooling coefficient, c, was observed to be lower for longer heating times. The temperatures obtained by extrapolation were estimated to have an accuracy of \pm 6 ${ }^{\circ} \mathrm{C}$.

The variation in the cooling coefficient after microwave heating for different lengths of time is outside the limits of error (estimated to be \pm 0.0002 ) and almost certainly arises because the effective heat capacity of the system increases with heating time as more of the surrounding tubing becomes hot. After very short heating times, the sample temperature will be higher than either the temperature of the quartz wool and tubing or the ambient temperature, $T_{0}$. Thus, heat will be lost rapidly from the catalyst sample to the reactor walls, and then to the surroundings, both of which will be relatively cool. After longer heating times, the tubing will have been heated, and the value of $c$ will be determined by the rate of heat loss to the surroundings from the reactor tube as a whole.

(b) Variation of Temperature with Microwave Heating Time. Figures 4-6 show the variation of temperature with time at different input microwave power levels for the three catalysts used. To obtain the data the sample was heated for $1 \mathrm{~min}$, the microwave power was switched off, and the thermocouple was inserted into the catalyst bed. This procedure was then 


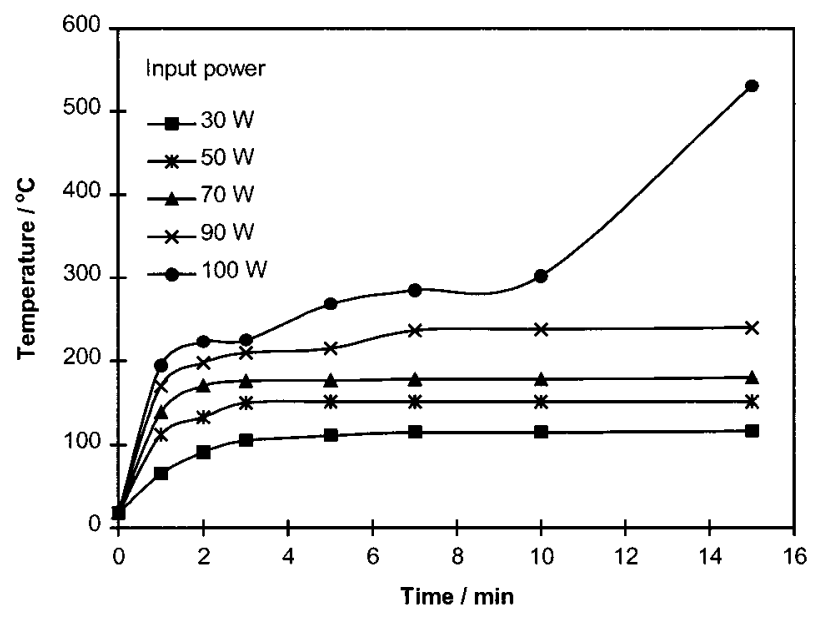

Figure 5. Temperature versus time for microwave heating of an $8 \%$ Pt/alumina catalyst at different input power levels.

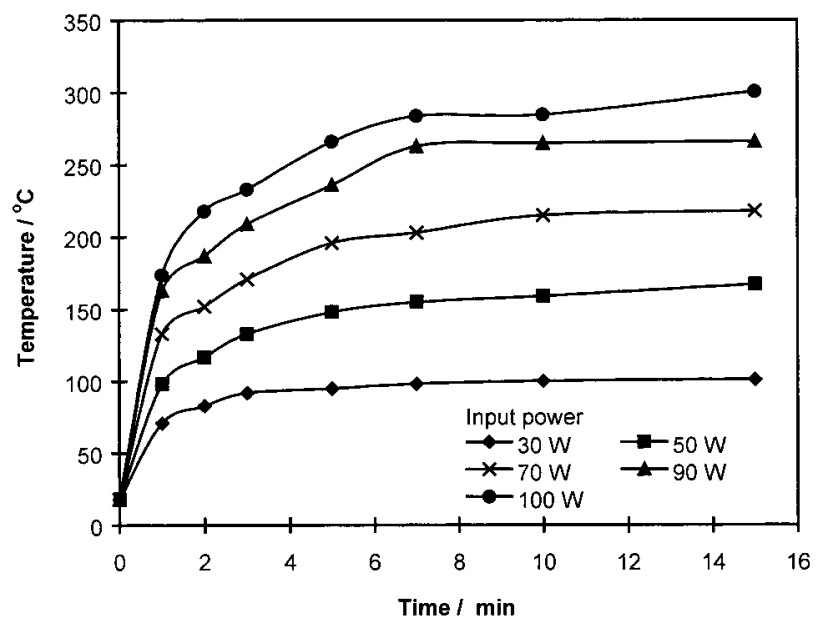

Figure 6. Temperature versus time for microwave heating of an $8 \% \mathrm{MoS}_{2} /$ silica catalyst at different input power levels.

repeated for progressively longer heating times. All of the catalysts showed the same type of behavior at low input power levels. This consisted of a rapid rise in temperature during the first minute of microwave heating, followed by a more gradual rise until the temperature reached a constant value after about $7 \mathrm{~min}$ of heating. At higher power input levels, there appeared to be a critical input power level above which the fraction of the power that was absorbed increased markedly with rising temperature and resulted in a thermal "runaway". The critical input power levels were about $70 \mathrm{~W}$ for the $\mathrm{MoS}_{2} / \mathrm{Al}_{2} \mathrm{O}_{3}$ catalyst and $100 \mathrm{~W}$ for the Pt/AI ${ }_{2} \mathrm{O}_{3}$ catalyst. The $\mathrm{MoS}_{2} / \mathrm{SiO}_{2}$ catalyst did not show thermal runaway in the temperature range studied, although there were some signs of temperature drift after long times at $100-\mathrm{W}$ power input.

The $\mathrm{Pt} / \mathrm{Al}_{2} \mathrm{O}_{3}$ catalyst showed the most dramatic effect, the temperature reaching an almost constant value of $285^{\circ} \mathrm{C}$ after $7 \mathrm{~min}$ of heating before rising again strongly at longer heating times. This type of behavior is expected when the absorbed power/temperature curve just touches the straight line representing the rate of heat loss, as shown by the dotted curve in Figure 1. At the point of contact, the rate of power absorbed is equal to the rate of heat loss, and the rate of temperature rise should temporarily be equal to zero.

(c) Effect of $\mathrm{MoS}_{2}$ Loading on Heating Characteristics of the Alumina-Supported Catalysts. Fig-

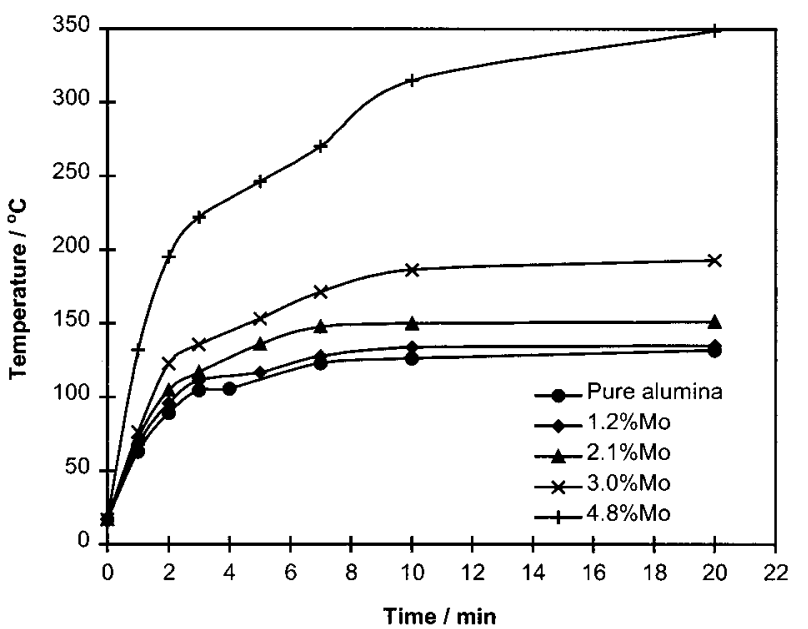

Figure 7. Temperature versus time of microwave heating for alumina-supported catalysts containing different amounts of molybdenum. The input power remained constant at $65 \mathrm{~W}$.

ure 7 shows the variation of temperature with time for pure alumina and a series of $\mathrm{MoS}_{2} / \mathrm{Al}_{2} \mathrm{O}_{3}$ catalysts containing different loadings of molybdenum. Each sample was heated by a microwave source with a constant input power of $65 \mathrm{~W}$. It can be seen that low loadings of molybdenum had very little effect on the heating characteristics of the catalyst, and it was only when the concentration of molybdenum rose above 2.1 wt \% that significant enhancement of the heating occurred. This effect can be attributed to the formation of a very stable molybdate species on the alumina surface at low loadings, which cannot easily be converted into molybdenum sulfide. Because of its layer structure, molybdenum sulfide has a much higher effective dielectric loss factor than most oxides and is likely to be responsible for most of the enhanced heating.

Reardon et al. 22 have shown that aqueous mol ybdates react preferentially with type I hydroxyl species on alumina surfaces. These hydroxyl groups are associated with tetrahedral aluminum atoms, and the $\mathrm{MoO}_{4}{ }^{2-}$ species formed were found to be very difficult to sulfide. It was only after these particular hydroxyl groups had been saturated that adsorbed molybdate species could be converted to molybdenum sulfide. From the results shown in Figure 7, it is estimated that the first $1.8 \mathrm{wt}$ $\%$ of molybdenum adsorbed on the alumina remains in the oxide state. As a result, the amount of molybdenum sulfide formed is significantly less than might be expected, being reduced from a nominal $8 \%$ to $5 \%$ for the most highly loaded sample.

Bulk $\mathrm{MoS}_{2}$ has a layer structure with alternating sheets of sulfur and molybdenum atoms, and there is spectroscopic and electron microscopic evidence that rafts of this structure are formed on the surface of $\gamma$-alumina. ${ }^{23}$ On the (111) plane of al umina, these rafts are oriented with their basal planes perpendicular to the surface, but on the (100) plane, the basal planes are parallel to the surface. ${ }^{24}$ In both cases, the molybdenum sulfide retains its bulk structure and is likely to have an effective dielectric loss factor similar to that of the bulk compound.

If it is assumed that $\mathrm{MoS}_{2}$ in the catalyst behaves like bulk $\mathrm{MoS}_{2}$ and that interfacial effects can be ignored, it is possible to make a rough estimate of the relative values of $\epsilon_{\text {eff }}^{\prime \prime}$ for alumina and $\mathrm{MoS}_{2}$ in the catalyst by examining the heating curves shown in Figure 7. The temperature rise achieved with pure alumina at the 


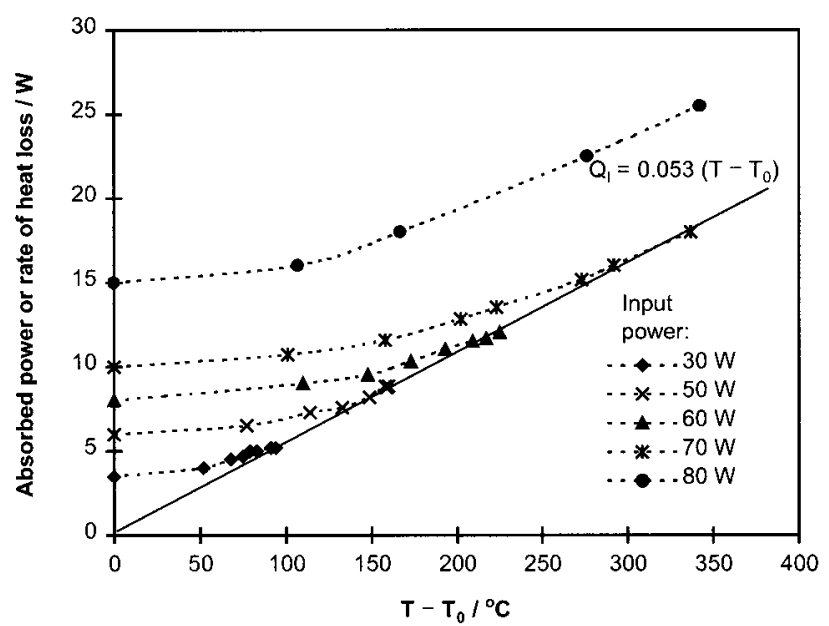

Figure 8. Absorbed microwave power versus temperature for a nominal $8 \% \mathrm{MoS}_{2} / \mathrm{Al}_{2} \mathrm{O}_{3}$ catalyst at different input power levels. $\mathrm{T}_{0}=18^{\circ} \mathrm{C}$.

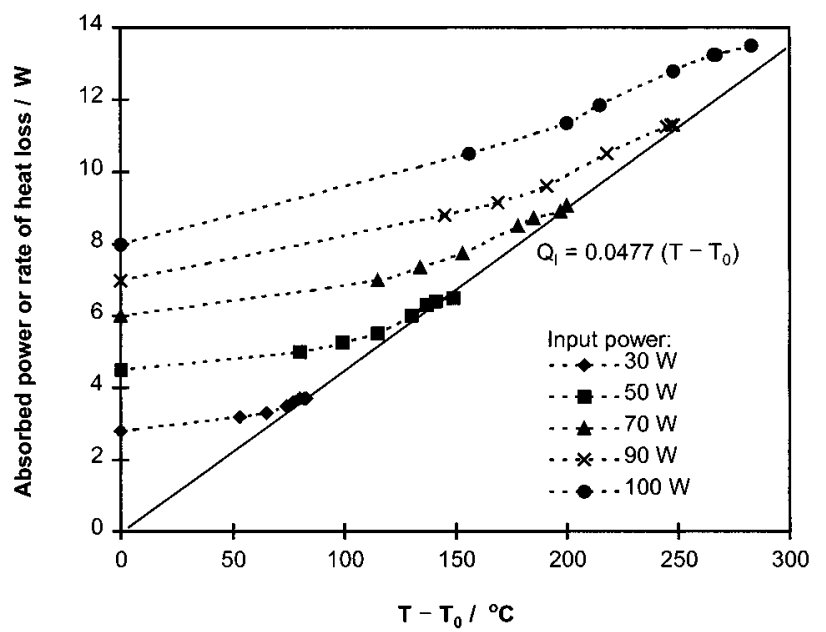

Figure 9. Absorbed microwave power versus temperature for an $8 \% \mathrm{MoS}_{2} / \mathrm{SiO}_{2}$ catalyst at different input power levels. $\mathrm{T}_{0}=18$ ${ }^{\circ} \mathrm{C}$.

steady state is $109^{\circ} \mathrm{C}$, compared to a rise of $170{ }^{\circ} \mathrm{C}$ with the catalyst containing 3\% molybdenum. After all owing for the amount of molybdenum remaining as oxide, the proportion by weight of molybdenum sulfide in this catalyst is estimated to be $2 \%$. At the steady state, the power absorbed by the catalyst should be directly proportional to the temperature rise because it has been shown (see next section) that the rate of heat loss follows eq 4. On this basis, the ratio of the effective dielectric loss factors for $\mathrm{MoS}_{2}$ and alumina is calculated to be around 28 . This value can be compared with dielectric measurements ${ }^{9}$ made at $200{ }^{\circ} \mathrm{C}$ and a frequency of 2.216 $\mathrm{GHz}$, which show $\epsilon_{\text {eff }}^{\prime \prime}$ to be equal to 0.85 for bulk $\mathrm{MoS}_{2}$ and 0.025 for pure alumina, giving a ratio of 34 . Considering the approximations that have been made in this calculation, the agreement between the two ratios is good and lends support to the contention that molybdenum sulfide retains its bulk structure and interacts only weakly with the alumina surface.

(d) Conditions for Thermal Runaway. Figures 8-10 show the microwave power absorbed by $\mathrm{MoS}_{2} /$ $\mathrm{Al}_{2} \mathrm{O}_{3}, \mathrm{MoS}_{2} / \mathrm{SiO}_{2}$, and $\mathrm{Pt} / \mathrm{Al}_{2} \mathrm{O}_{3}$ catalysts, respectively, as a function of temperature at different fixed input power levels. The data points correspond to microwave heating times of $0,1,2,3,5,7,10$, and $15 \mathrm{~min}$, and for low input power, they tend to converge at long heating

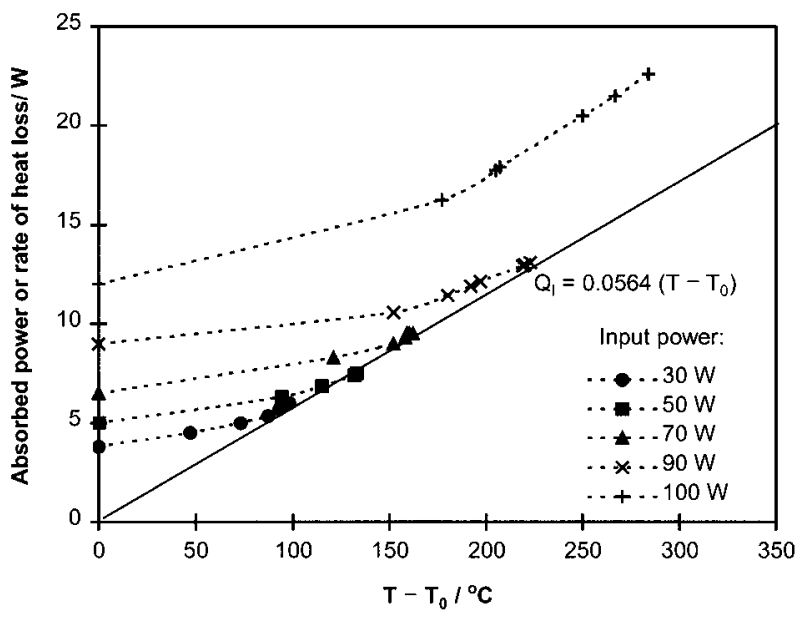

Figure 10. Absorbed microwave power versus temperature for an $8 \% \mathrm{Pt} / \mathrm{Al}_{2} \mathrm{O}_{3}$ catalyst at different input power levels. $\mathrm{T}_{0}=18$ ${ }^{\circ} \mathrm{C}$.

times as the system reaches a constant temperature. The data points corresponding to the steady state are found to lie on a straight line that passes through the origin of the graph. Because the rate of power absorbed is equal to the rate of heat loss at the steady-state, this linear relationship indicates that the rate of heat loss is proportional to the temperature difference and follows eq 4. The heat transfer coefficients, $\alpha$, are cal culated to be $0.0533,0.0477$, and $0.0564 \mathrm{~W} /{ }^{\circ} \mathrm{C}$ for the $\mathrm{MoS}_{2} / \mathrm{Al}_{2} \mathrm{O}_{3}$, $\mathrm{MoS}_{2} / \mathrm{SiO}_{2}$, and $\mathrm{Pt} / \mathrm{Al}_{2} \mathrm{O}_{3}$ catalysts, respectively.

Thermal runaway occurs when the plot of power absorbed versus temperature lies entirely above the straight line representing the heat loss. This occurs with $\mathrm{MoS}_{2} / \mathrm{Al}_{2} \mathrm{O}_{3}$ at $80-\mathrm{W}$ input power. There is also a critical power input of $70 \mathrm{~W}$ at which the power absorbed comes very close to the straight line and the temperature continues to rise, al beit slowly. This situation can arise when, at fixed input power, the temperature coefficient of the absorbed power, $\mathrm{dP}_{\mathrm{abs}} / \mathrm{dT}$, becomes equal to $\alpha$ Equation 6 can then be satisfied for a whole range of temperatures, and there is a tendency for "temperature creep" to occur. The Pt/Al ${ }_{2} \mathrm{O}_{3}$ catalyst showed similar behavior, with the critical input power lying somewhere between 90 and $100 \mathrm{~W}$.

With the $\mathrm{MoS}_{2} / \mathrm{SiO}_{2}$ catalyst, the plot of power absorbed versus temperature appeared to cross the straight line representing the rate of heat loss right up to the highest input power used, and no thermal runaway was observed.

(e) Variation of the Power Absorbed by the Catalyst as a Function of Temperature. From eq 3 , the average power absorbed by the catalyst, $\mathrm{P}_{\mathrm{abs}}$, should be proportional to $\epsilon_{\text {eff }}^{\prime \prime} E_{r m s}{ }^{2}$ at constant frequency. Although $E_{r m s}$ is unknown, its value for a particular configuration of the cavity and catalyst will be proportional to the square root of the input power, ${ }^{19}$ $P_{\text {in, }}$, and hence, the ratio $P_{a b s} / P_{\text {in }}$ should be roughly proportional to $\epsilon_{\text {eff. }}^{\prime \prime}$ Figure 11 shows the variation of this quantity, designated as $\gamma$, with temperature for the three catalysts used. It can be seen that the aluminasupported catalysts are more efficient absorbers of microwave power than the silica-supported catalyst. This difference arises mainly because alumina has a higher effective dielectric loss factor than silica (0.01 and 0.0026 , respectively, at $25^{\circ} \mathrm{C}$ ). ${ }^{19}$ It is also noteworthy that $\gamma$ for $\mathrm{Pt} / \mathrm{Al}_{2} \mathrm{O}_{3}$ has a much higher temperature coefficient than that for $\mathrm{MoS}_{2} / \mathrm{Al}_{2} \mathrm{O}_{3}$. 


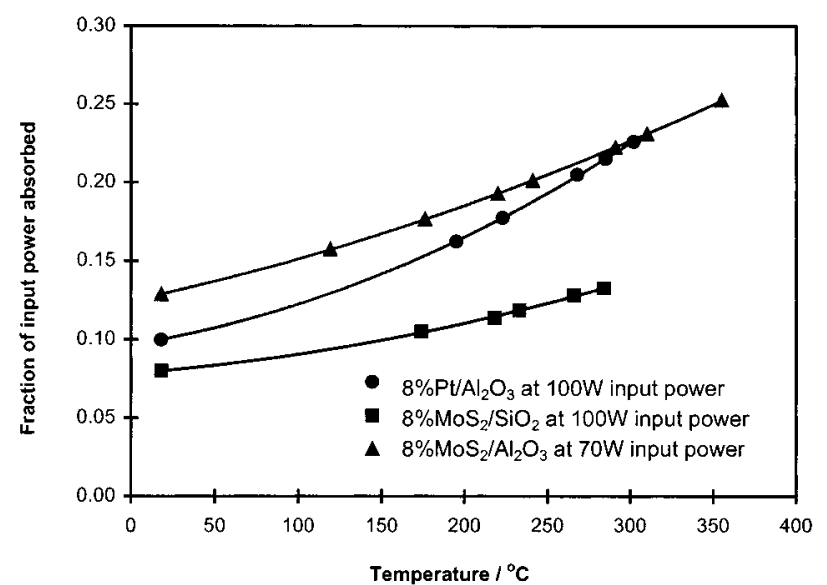

Figure 11. Plots of $\gamma$ versus temperature for the three catalysts.

According to Kenkre et al., ${ }^{25}$ there are two types of microwave-absorbing entities present in ceramic materials. The first, referred to as type A, are localized absorbing entities, which contribute a temperatureindependent term to $\epsilon_{\text {eff }}^{\prime \prime}$. The second, referred to as type M, are interstitial atoms or vacancies, which are localized in shallow potential wells at low temperatures but become mobile at higher temperatures. The strong increase in $\epsilon_{\text {eff }}^{\prime \prime}$ with temperature is thought to be caused by the increased mobility of these type $M$ absorbers. If the activation energy required to cause these entities to become mobile is $E_{a}$, then the fraction, $f(T)$, that is mobile at a given temperature is given by the equation

$$
f(T)=\exp \left(-\frac{E_{a}}{R T}\right)\left[\exp \left(-\frac{E_{a}}{R T}\right)+1\right]^{-1}
$$

When $E_{a} \gg R T$, this equation can be simplified to

$$
f(T)=\exp \left(-\frac{E_{a}}{R T}\right)
$$

The variation of $\epsilon_{\text {eff }}^{\prime \prime}$ with temperature can then be written as

$$
\epsilon_{\text {eff }}^{\prime \prime}=k_{A}+k_{M} \exp \left(-\frac{E_{a}}{R T}\right)
$$

where the constants $k_{A}$ and $k_{M}$ are measures of the contributions made by localized and mobile microwave absorbers, respectively. form

This equation has been tested against our data in the

$$
\gamma=c_{A}+c_{M} \exp \left(-\frac{E_{a}}{R T}\right)
$$

where $\mathrm{C}_{\mathrm{A}}$ and $\mathrm{C}_{\mathrm{M}}$ are constants. Figure 12 shows a plot of $\ln (\gamma-0.113)$ versus $1 / \mathrm{T}$ for the $\mathrm{MoS}_{2} / \mathrm{Al}_{2} \mathrm{O}_{3}$ catalyst at 70-W input power. All of the points lie on a straight line, showing that eq 12 accurately describes the data. Equally good plots were obtained for input powers of 30 and $60 \mathrm{~W}$ with $\mathrm{MoS}_{2} / \mathrm{Al}_{2} \mathrm{O}_{3}$ and for 100 and $90 \mathrm{~W}$ with $\mathrm{MoS}_{2} / \mathrm{SiO}_{2}$. The results obtained with the Pt/Al ${ }_{2} \mathrm{O}_{3}$ catalyst were less satisfactory, and consistent values for the constants in eq 12 could not be obtained. The average values found for $C_{A}, C_{M}$, and $E_{a}$ with the molybdenum sulfide catalysts are listed in Table 1 . On the basis of these data, it is estimated that thermal

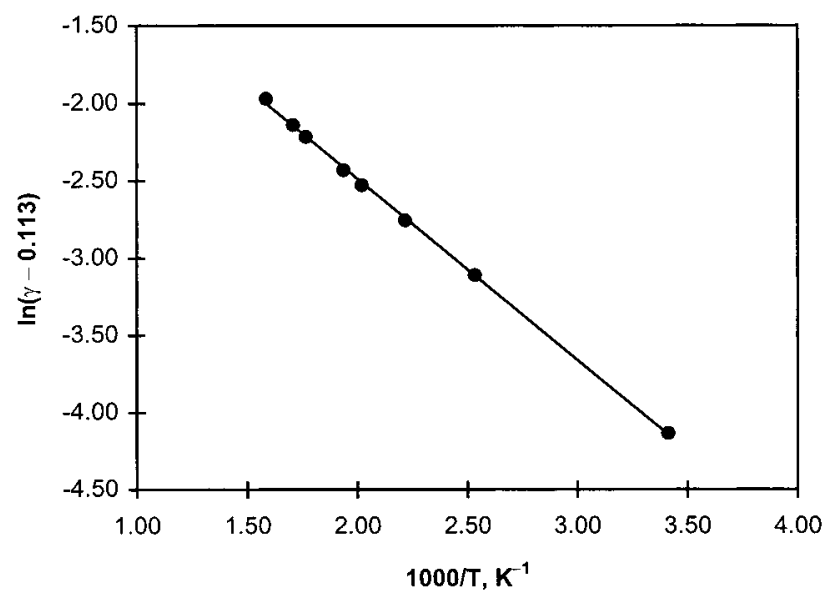

Figure 12. Plot of $\ln (\gamma-0.113)$ versus $1000 / \mathrm{T}$ for $\mathrm{MoS}_{2} / \mathrm{Al}_{2} \mathrm{O}_{3}$ at 70-W input power.

Table 1. Values of the Constants Contained in Eq 12 for the Molybdenum Catalysts

\begin{tabular}{lccc}
\hline \multicolumn{1}{c}{ catalyst } & $\mathrm{C}_{\mathrm{A}}$ & $\mathrm{C}_{M}$ & $\mathrm{E}_{\mathrm{a}}\left(\mathrm{kJ} \mathrm{mol}{ }^{-1}\right)$ \\
\hline $\mathrm{MoS}_{2} / \mathrm{Al}_{2} \mathrm{O}_{3}$ & $0.113 \pm 0.003$ & $0.80 \pm 0.07$ & $9.3 \pm 0.5$ \\
$\mathrm{MoS}_{2} / \mathrm{SiO}_{2}$ & $0.072 \pm 0.001$ & $0.63 \pm 0.03$ & $11.1 \pm 0.6$
\end{tabular}

runaway would occur with the $\mathrm{MoS}_{2} / \mathrm{SiO}_{2}$ catalyst at temperatures in excess of $350{ }^{\circ} \mathrm{C}$.

The activation energies obtained with $\mathrm{MoS}_{2} / \mathrm{Al}_{2} \mathrm{O}_{3}$ and $\mathrm{MoS}_{2} / \mathrm{SiO}_{2}$ are much lower than the values of 21.6 and $46.5 \mathrm{~kJ} \mathrm{~mol}{ }^{-1}$ calculated by Kenkre et al. ${ }^{25}$ for pure alumina and silica, respectively. This shows that the mobile absorbing entities are not associated with the support material but must be located either in the catalyst material or at the catalyst-support interface. If the bulk properties of molybdenum sulfide were primarily responsible for the temperature-dependent microwave absorption, then the activation energies for the two catalysts would have similar values. In fact, the activation energy obtained for $\mathrm{MoS}_{2} / \mathrm{SiO}_{2}$ was found to be marginally higher than that for $\mathrm{MoS}_{2} / \mathrm{Al}_{2} \mathrm{O}_{3}$, which might indicate that the interface does make a significant contribution to the overall absorption of microwave radiation.

The model used by Kenkre et al. ${ }^{25}$ is unlikely to apply to the $\mathrm{Pt} / \mathrm{Al}_{2} \mathrm{O}_{3}$ catalyst, where the platinum tends to form small conducting particles. The dielectric loss arising from interfacial polarization in a system composed of a conducting phase dispersed in a lossfree medium has been examined by a number of authors. ${ }^{14,26,27}$ In particular Perry et al. ${ }^{14}$ examined microwave absorption in small platinum crystallites supported on alumina and used the following expression for the dielectric loss factor

$$
\epsilon_{\text {eff }}^{\prime \prime}=9 \epsilon_{\mathrm{m}}{ }^{2 \omega \epsilon_{0} \mathrm{v}} \frac{}{\sigma}
$$

Here, $\epsilon_{m}$ is the permittivity of the medium, $\epsilon_{0}$ is the vacuum permittivity, $\omega$ is the radiation frequency, $v$ is the volume fraction of the conducting phase, and $\sigma$ is the conductivity of the metallic particles. The conductivity varies with particle diameter, d, according to the equation

$$
\sigma=\frac{\sigma(\infty)}{1+\lambda / d}
$$

where $\sigma(\infty)$ is the bulk conductivity and $\lambda$ is the electron 
mean free path. For platinum, $\lambda$ is equal to $7.5 \mathrm{~nm}$, and the bulk conductivity can be used with reasonable accuracy for particles with diameters greater than 50 $\mathrm{nm}$.

The main temperature-dependent term in eq 12 is the conductivity. For platinum, 1/ $\sigma$ varies almost linearly with temperature from $10.7(\Omega \mathrm{m})^{-1}$ at $298 \mathrm{~K}$ to 21.9 $(\Omega \mathrm{m})^{-1}$ at $600 \mathrm{~K}$. Thus, the value of $\epsilon_{\mathrm{eff}}^{\prime \prime}$ should more than double over this temperature range. This is more or less what is found in Figure 11, but the variation with temperature is far from linear, showing that eq 13 is not followed accurately. This difference from linearity could arise either because the model used is oversimplified or because of the existence of very small platinum clusters, which do not show true metallic conductivity.

\section{Conclusions}

It has been demonstrated that thermal runaway occurs with the $8 \% \mathrm{MoS}_{2} / \mathrm{Al}_{2} \mathrm{O}_{3}$ and $8 \% \mathrm{Pt} / \mathrm{Al}_{2} \mathrm{O}_{3}$ catalysts in the temperature range $285-300{ }^{\circ} \mathrm{C}$ under conditions where the power dissipated within the catalyst begins to rise with temperature at a rate faster than the rate of cooling. The critical temperature is highly dependent on the rate of cooling of the catalyst and varies with the experimental setup. In our system, where temperatures up to $400{ }^{\circ} \mathrm{C}$ were achieved, the rate of cooling was found to be directly proportional to the difference in temperature between the catalyst and the surroundings, showing that conductive and convective heat losses were predominant. This would not be true at much higher temperatures, where the occurrence of appreciable heat losses due to radiation could have a profound effect on the conditions required for thermal runaway.

For $\mathrm{MoS}_{2} / \mathrm{Al}_{2} \mathrm{O}_{3}$ catalysts, it has been shown that low loadings of molybdenum do not contribute to the microwave heating effect. This is thought to occur because part of the molybdenum salt impregnated onto the alumina support forms a particularly stable oxide that cannot be converted into molybdenum sulfide, the compound mainly responsible for enhanced microwave absorption.

For $\mathrm{MoS}_{2} / \mathrm{Al}_{2} \mathrm{O}_{3}$ and $\mathrm{MoS}_{2} / \mathrm{SiO}_{2}$, the fraction, $\gamma$, of the microwave power that is absorbed by the catalyst is found to increase with temperature according to the relation

$$
\gamma=c_{A}+c_{M} \exp \left(-\frac{E_{a}}{R T}\right)
$$

where the two terms represent the contributions made by localized and mobile microwave absorbers, respectively. The broad similarity between the values of $C_{M}$ and $\mathrm{E}_{\mathrm{a}}$ obtained for the two catalysts is an indication that the mobile absorbers are mainly located in the $\mathrm{MoS}_{2}$ component. However, there is a small, but significant, difference in the activation energies, which might indicate that the interface between $\mathrm{MoS}_{2}$ and the support has an appreciable influence on the dielectric properties of the $\mathrm{MoS}_{2}$ layers.

The $\mathrm{Pt} / \mathrm{Al}_{2} \mathrm{O}_{3}$ catalyst showed a strong variation of $\gamma$ with temperature that could not be described adequately by the above equation. The overall magnitude of the increase was in keeping with a model consisting of conducting spheres dispersed in a loss-free medium, but $\gamma$ did not vary linearly with temperature as predicted.

\section{Literature Cited}

(1) Thiebaut, J. M.; Roussy, G.; Medjram, M. S.; Garin, F.; Seyfried, L.; Maire, G. Durable Changes of the Catalytic Properties of Alumina-Supported Platinum Induced by Microwave I rradiation. Catal. Lett. 1993, 21, 133.

(2) Roussy, G.; Thiebaut, J. M.; Souiri, M.; Marchal, E.; Kiennemann, A.; Maire, G. Controlled Oxidation of Methane Doped Catalysts Irradiated by Microwaves. Catal. Today 1994, 21, 349.

(3) Chen, C.; Hong, P.; Dai, S.; Kan, J . Microwave Effects on the Oxidative Coupling of Methane over Proton Conductive Catalysts. J . Chem. Soc., Faraday Trans. 1995, 91, 1179.

(4) Martin-Aranda, R. M.; Rojas-Cervantes, M. L.; LopezPeinado, A. J .; Lopez-Gonzales, J . D. Selective N-Propargylation of I midazol e under Microwave I rradiation Using Some Magnesium Oxides as Catalysts. Catal. Lett. 1994, 25, 385.

(5) Roussy, G.; Hilaire, S.; Thiebaut, J. M.; Maire, G.; Garin, F.; Ringler, S. Permanent Change of Catalytic Properties I nduced by $\mathrm{Microwave}$ Activation on $0.3 \% \mathrm{Pt} / \mathrm{Al}_{2} \mathrm{O}_{3}$ (Europt-3) and on $0.3 \%$ Pt 0.3\% Re/Al ${ }_{2} \mathrm{O}_{3}$ (Europt-4). Appl. Catal. A: Gen. 1997, 156, 167.

(6) Roussy, G.; Marchal, E.; Thiebaut, J . M.; Kiennemann, A.; Maire, G. C-2(+) Selectivity Enhancement in Oxidative Coupling of Methane over Microwave-I rradiated Catalysts. Fuel Process. Technol. 1997, 50, 261.

(7) Bond, G.; Moyes, R. B.; Whan, D. A. Recent Applications of Microwave-Heating in Catalysis. Catal. Today 1993, 17, 423.

(8) Zhang, X. L.; Hayward, D. O.; Mingos, D. M. P. Apparent Equilibrium Shifts and Hot-Spot Formation for Catalytic Reactions Induced by Microwave Dielectric Heating. Chem. Commun. 1999, 975.

(9) Zhang, X. L. Studies on Heterogeneous Catalysis Using Microwave and Conventional Heating. Ph.D. Thesis, University of London, London, 2000.

(10) Stuerga, D. A. C.; Gaillard, P. J . Microwave Athermal Effects in Chemistry: A Myth's Autopsy. 1. Historical Background and Fundamentals of Wave-Matter Interaction. J. Microwave Power Electromagn. Energy 1996, 31, 87.

(11) Stuerga, D. A. C.; Gaillard, P. J. Microwave Athermal Effects in Chemistry: A Myth's Autopsy. 2. Orienting Effects and Thermodynamic Consequences of Electric Field. J. Microwave Power Electromagn. Energy 1996, 31, 101.

(12) Thomas, J . Particle Size Effect in Microwave-Enhanced Catalysis. Catal. Lett. 1997, 49, 137.

(13) Vos, B.; Poels, E. K.; Bliek, A. Presented at the International Conference on Microwave Chemistry, Prague, Czech Republic, Sept 6-11, 1998.

(14) Perry, W. L.; Cooke, D. W.; Katz, J. D.; Datye, A. K. On the Possibility of a Significant Temperature Gradient in Supported Metal Catalysts Subjected to Microwave Heating. Catal. Lett. 1997, 47, 1.

(15) Perry, W. L.; Katz, J . D.; Rees, D.; Paffet, M. T.; Datye, A. K. Kinetics of the Microwave-Heated CO Oxidation Reaction over Alumina-Supported Pd and Pt Catalysts. J . Catal. 1997, 171, 431.

(16) Zhang X. L.; Hayward D. O.; Lee, C. M.; Mingos, D. M. P. Microwave Assisted Catalytic Reduction of Sulfur Dioxide with Methane over $\mathrm{MoS}_{2}$ Catalysts. Appl. Catal. B: Environ. 2001, 863, $1-12$.

(17) Inglesias, J .; Westphall, W. B. Technical Report 203; Massachusetts I nstitute of Technology: Cambridge, MA, J an 1967.

(18) Couderc, D.; Giroux, M.; Bosisio, R. G. Dynamic HighTemperature Microwave Complex Permittivity Measurements on Samples Heated via Microwave Absorption. J . Microwave Power 1973, 8, 69 .

(19) Metaxas, A. C.; Meredith, R. J. Industrial Microwave Heating; Peter Peregrinus Ltd: London, 1983.

(20) Coelho, R. Physics of Dielectrics for Engineers; Elsevier Publishing Co.: Amsterdam, 1979.

(21) Carslaw, H. S.; J aeger, J . C. Conduction of Heat in Solids, 2nd ed.; Clarendon Press: Oxford, U.K., 1959.

(22) Reardon, J .; Datye, A. K.; Sault, A. G. Tailoring Alumina Surface Chemistry for Efficient Use of Supported MoS 2. J . Catal. 1998, 173, 145.

(23) Hayden, T. F.; Dumesic, J . A. Studies of the Structure of Molybdenum Oxide and Sulfide Supported on Thin-Films of Alumina. J . Catal. 1987, 103, 366.

(24) Sakashita, Y.; Yoneda, T. Orientation of $\mathrm{MoS}_{2}$ Clusters Supported on Two Kinds of Gamma- $\mathrm{Al}_{2} \mathrm{O}_{3}$ Single-Crystal Surfaces with Different Indices. J . Catal. 1999, 185, 487. 
(25) Kenkre, V. M.; Skala, L.; Weiser, M. W.; Katz, J . D. Theory of Microwave Interactions in Ceramic Materials-The Phenomenon of Thermal Runaway. J . Mater. Sci. 1991, 26, 2483.

(26) Thiebaut, J. M.; Mbotto, J .; Bessiere, J.; Roussy, G. Dielectric Measurements of Solid-Solution Systems-Application to the Activation of the Sphalerite by a Cupric Solution. J . Chim. Phys. Phys.-Chim. Bio. 1985, 82, 401.
(27) Hamon, B. V. Maxwell-Wagner Loss and Absorption Currents in Dielectrics. Aust. J . Phys. 1953, 6, 304.

Received for review August 29, 2000 Revised manuscript received March 6, 2001

Accepted April 24, 2001

IE 0007825 